Article

\title{
Copper Nanowires Modified with Graphene Oxide Nanosheets for Simultaneous Voltammetric Determination of Ascorbic Acid, Dopamine and Acetaminophen
}

\author{
Wanting Hao ${ }^{1, \dagger}$, Yuchan Zhang ${ }^{1, \dagger}{ }^{\text {, Jingchuan Fan }}{ }^{1}$, Handeng Liu ${ }^{1}$, Qi Shi ${ }^{1}$, Weichi Liu ${ }^{1}$, \\ Qianyu Peng ${ }^{1}$ and Guangchao Zang 1,2,*(D) \\ 1 Institute of Life Science, and Laboratory of Tissue and Cell Biology, Lab Teaching \& Management Center, \\ Chongqing Medical University, Chongqing 400016, China; HWThally@163.com (W.H.); \\ zhangyc@cqmu.edu.cn (Y.Z.); fanjc@cqmu.edu.cn (J.F.); hdliu@cqmu.edu.cn (H.L.); \\ sq1139188112@163.com (Q.S.); 1wc805447132@163.com (W.L.); 13996689178@163.com (Q.P.) \\ 2 Key Laboratory of Laboratory Medical Diagnostics of Education, Department of Laboratory Medicine, \\ Chongqing Medical University, Chongqing 400016, China \\ * Correspondence: zangguangchao@126.com; Tel.: +86-23-6366-2443 \\ + These authors contributed equally to this work.
}

Academic Editor: Ondrej Zitka

Received: 25 May 2019; Accepted: 21 June 2019; Published: 24 June 2019

\begin{abstract}
Copper nanowires ( $\mathrm{Cu}$ NWs) were modified with graphene oxide (GO) nanosheets to obtain a sensor for simultaneous voltammetric determination of ascorbic acid (AA), dopamine (DA) and acetaminophen (AC). The nanocomposite was obtained via sonication, and its structures were characterized by scanning electron microscopy (SEM), X-ray diffraction (XRD) and energy-dispersive $X$-ray spectroscopy (EDS). The electrochemical oxidation activity of the materials (placed on a glassy carbon electrode) was studied by cyclic voltammetry and differential pulse voltammetry. Due to the synergistic effect of $\mathrm{Cu}$ NWs and GO, the specific surface, electrochemical oxidation performance and conductivity are improved when compared to each individual component. The peaks for AA $(-0.08 \mathrm{~V}), \mathrm{DA}(+0.16 \mathrm{~V})$, and $\mathrm{AC}(+0.38 \mathrm{~V})$ are well separated. The sensor has wide linear ranges which are from 1-60 $\mu \mathrm{M}, 1-100 \mu \mathrm{M}$, and 1-100 $\mu \mathrm{M}$ for AA, DA, and AC, respectively, when operated in the differential pulse voltammetric mode. The detection limits are 50, 410 and $40 \mathrm{nM}$, respectively. Potential interferences by uric acid $(20 \mu \mathrm{M})$, glucose $(10 \mathrm{mM}), \mathrm{NaCl}(1 \mathrm{mM})$, and $\mathrm{KCl}(1 \mathrm{mM})$ were tested for AA $(1 \mu \mathrm{M}), \mathrm{DA}(1 \mu \mathrm{M})$, and $\mathrm{AC}(1 \mu \mathrm{M})$ and were found to be insignificant. The method was successfully applied to the quantification of AA, DA, and AC in spiked serum samples.
\end{abstract}

Keywords: cyclic voltammetry; differential pulse voltammetry; synergistic effect; antioxidant; excitatory neurotransmitter; analgesic

\section{Introduction}

Ascorbic acid (AA), dopamine (DA), and acetaminophen (AC) are considered to be crucial molecules that commonly coexist in human metabolic fluid [1-4]. Ascorbic acid, a vital vitamin in the human diet, has a major role in bioelectrochemistry, neurochemistry and clinical diagnostic applications [5]. Such antioxidants help prevent acquired immune deficiency syndrome (AIDS), cancer, scurvy, hepatic disease, mental illness, and the common cold [6-10]. Dopamine, a chemical compound found in the brain, acts as a significant excitatory neurotransmitter to regulate system functions, such as renal, hormonal systems, and the central nervous system [1,11-13]. A lack of DA will lead to nervous system disease, for instance schizophrenia or Parkinson's disease $[2,14]$. 
Acetaminophen, a well-established over the counter (OTC) drug used worldwide, is well known as an analgesic and antipyretic for relieving pain associated with toothache, headache, muscle aches, colds, fevers, postoperative pain, etc. [15-17]. Moreover, it has been reported as a potential prodrug for resistant cancer therapy [18]. Overdoses of AC can induce side effects, such as severe and sometimes fatal hepatotoxicity and nephrotoxicity $[1,19,20]$. Higher concentration levels of AA, DA and AC are associated with a higher risk of various diseases linked to human health management and treatment. Thus, exploring a high-performance analytical method to realize good sensitivity to these three compounds simultaneous determination is an urgent need.

Electrochemical techniques are well known, and fast, simple, sensitive, selective, reliable and low-cost characteristics have been developed alongside analysis of multiple components in biological matrices. Lots of studies have reported the feasibility of realizing the simultaneous determination of two to five components commonly containing uric acid (UA), DA, and AA. Nevertheless, it is very difficult to simultaneously test AA, DA, and AC, as the three chemical compounds have semblable electrochemical performances, and their oxidation peak potentials are not clearly separated on many electrodes, greatly complicating their electrochemical discrimination [16,21,22]. Only a minority of research efforts have been developed with various electrodes for simultaneous determination of AA, DA, and AC. For example, glassy carbon electrodes were modified with $\mathrm{Au} / \mathrm{ZnO} / \mathrm{N}$-doped graphene hybrid nanostructure [1] and phenylethynyl ferrocene thiolate-modified $\mathrm{Fe}_{3} \mathrm{O}_{4} @ \mathrm{Au}$ nanoparticles (NPs) were coupled with a graphene sheet/chitosan [16], individually, and a carbon paste electrode was modified with a PbS nanoparticles Schiff base [22]. These have been reported, and they demonstrate the electrochemical activity which occurs simultaneously with the three compounds oxidation. Although exhibiting improved electrochemical oxidization for peak separations of the three compounds, these electrodes are still not appropriate mass production objects for fabricating corresponding electrochemical sensors due to their high price and complexities resulting from many kinds of materials.

However, the aforementioned graphene nanosheet and its derivatives, such as N-doped graphene [1], as well as reduced graphene oxide (rGO) [23] and graphene oxide (GO) [24] based nanocomposites, display great potential application for fabricating electrochemical sensors, with superior performance attributable to good chemical stability, large specific surface area, admirable conductivity, relatively easy chemical modification, strong mechanical strength and flexibility, and high electrochemical activity for biomolecules. Among the various graphene derivatives, it is worth noting that GO is rich in epoxy, phenol, hydroxyl, and carboxylic acid groups, which is concomitant with strongly hydrophilic endowed GO good performance to modulate the electrode surface structure and properties [25-27]. For instance, multi-walled carbon nanotubes/GO/gold nanorods/glassy carbon electrode (GCE) shows an ultra-sensitive detection of AA with a low detection limit (LOD) of 0.85 nM [24]. In addition, a Co(II)-based zeolitic imidazolate framework (ZIF-67) and GO nanocomposite modified GCE was successfully simultaneously tested for DA and UA [28], and an electrochemical sensor based on GO-1,4-xylenediamine- $\mathrm{Mn}_{2} \mathrm{O}_{3}$ nanospheres nanocomposite was stable and sensitive for simultaneous determination of AA and paracetamol [29]. Furthermore, AgNPs-GO-poly(L-arginine) composite-modified GCE shows simultaneous determination of AA, DA, UA, and L-tryptophan [30]. The poly(glycine)/GO composite-based sensor significantly amplifies the electrochemical signal for the simultaneous detection of UA, DA, guanine and adenine [31]. These studies reveal that GO-based sensors have been proved to be a favourable alternative for application in simultaneous detection.

Metal nanowires, especially copper nanowires ( $\mathrm{Cu}$ NWs), with outstanding electrochemical performance, such as efficient electron transfer and high catalytic activity, are promising materials for the development of electrochemical sensors [32]. Thus, in this study, the specific property of Cu NWs and GO were combined to prepare a nanocomposite ( $\mathrm{Cu}$ NWs-GO) with synergistic integration of individual component to enhance the electrochemical characteristics for AA, DA, and AC simultaneous determination. This hybrid nanocomposite was prepared by a general protocol of ultrasound mixing. Differential pulse voltammetry (DPV) was carried out to investigate the electrochemical properties, which exhibit a wide linear range with a low detection limit of AA, DA, and AC. In addition, the 
proposed assay also demonstrates good selectivity against other conventional interfering substances. It also evaluates the reported method upon application in human serum samples, indicating the potential applicability for simultaneous determination of these analytes.

\section{Results and Discussion}

\subsection{Characterization of the Copper Nanowires-Graphene Oxide (Cu NWs-GO) Nanocomposite}

The typical scanning electron microscope (SEM) images of synthesized nanomaterials including $\mathrm{Cu}$ NWs, GO, and Cu NWs-GO nanocomposite are displayed in Figure 1a-c. One can see in Figure 1a that the size of $\mathrm{Cu} N W \mathrm{~s}$ is well-proportioned with a diameter of $150 \mathrm{~nm} \pm 50 \mathrm{~nm}$-the same as that reported in literature [33], endowing it with good sensing performance. The morphology of GO is crumpled (Figure 1b), giving it good flexibility and high specific surface area for the immobilization of a great many substances. The SEM image of the nanocomposite (Figure 1c) notably shows that Cu NWs are well distributed and interconnect on the GO surface, implying that the high specific surface with loose structure enhances catalytic activity. The successful formation of $\mathrm{Cu}$ NWs-GO nanocomposite is further demonstrated by X-ray diffraction (XRD), as shown in Figure 1d. The XRD results of the $\mathrm{Cu}$ NWs-GO nanocomposite reveal intense and sharp peaks centered at $2 \theta$ values of $* 10.834^{\circ}, 43.297^{\circ}$, $50.433^{\circ}, 74.130^{\circ}, 89.931^{\circ}$, and $95.139^{\circ}$, perfectly matching the ${ }^{*}(111),(111),(200),(220),(311)$, and (222) Miller indices, respectively. The $2 \theta$ value and Miller Index preceded by the asterisk is similar to the GO surface (Figure S1a) [34-36], and the other peaks are from the Cu NWs (Figure S1b) [33] within the Cu NWs-GO nanocomposite. The energy-dispersive X-ray spectroscopy (EDS) analysis in Figure 1e reveals the elemental composition of the prepared nanocomposite which shows the carbon, oxygen and copper elements, further proving the presence of $\mathrm{GO}$ and $\mathrm{Cu}$, separately.

\subsection{Voltammetric Behaviors of the Modified Electrode}

Cyclic voltammetry (CV) and DPV measurements were performed in $0.1 \mathrm{M}$ phosphate-buffered saline (PBS) ( $\mathrm{pH}$ 7.0) solution to evaluate the electrochemical property of $\mathrm{Cu}$ NWs-GO nanocomposite for simultaneous determination of AA, DA, and AC. Cyclic voltammetry was operated in the potential range from $-1 \mathrm{~V}$ to $+1 \mathrm{~V}$ with a scan rate of $100 \mathrm{mV} \mathrm{s}^{-1}$. As shown in the Figure $2 \mathrm{~A}$ curve a, no response is observed in the absence of the three components on Nafion/Cu NWs-GO/GCE. A pair of redox peaks at about $-0.05 \mathrm{~V}$ and $-0.25 \mathrm{~V}$ is observed when adding $\mathrm{AA}$, which is associated with the oxidation of hydroxyl groups to carbonyl groups of AA (curve b) [2,37-39]. A new couple of redox peaks at about $+0.2 \mathrm{~V}$ and $+0.15 \mathrm{~V}$ appeared with the continuing addition of DA, which corresponds to the redox reaction between DA and dopamine quinone (curve c) [5,40]. When AC coexisted with AA and DA in the PBS, a relatively low redox response of AC was acquired (curve $\mathrm{d}$ ). The oxidation peak located at $+0.4 \mathrm{~V}$ and the reduction peak at about $+0.37 \mathrm{~V}$ of $\mathrm{AC}$ can be attributed to the redox reaction between AC and the quinonoid [41]. Cyclic voltammetry results confirm that the anodic oxidation of the three target molecules is a reversible process with three well-defined pair of redox peaks and no overlapped current signal on $\mathrm{Cu}$ NWs-GO nanocomposite modified GCE.

Differential pulse voltammetry was also utilized to analyze application of the three constituents' simultaneous determination on account of the better resolution and higher sensitivity of this method. The DPV parameters that were carried out included a $50 \mathrm{mV}$ amplitude and voltage range of $-1 \mathrm{~V}$ to $+1 \mathrm{~V}$. Figure $2 \mathrm{~B}$ depicts the DPV recordings of the separate signal of AA, DA and AC at Nafion/Cu NWs-GO/GCE. It can be seen in curve a that an obvious peak at $-0.08 \mathrm{~V}$ appeared with the absence of the three components. This is caused by $\mathrm{Cu}$ NWs being easily oxidized to bivalent copper ions around $0 \mathrm{~V}$ during the positive scan [25,33]. Although the peak appeared here is consistent with the oxidation peak potential of AA, it does not affect the detection of AA as the twice response signal generated by adding AA (curve b). The result demonstrates the superiority of GO combined with $\mathrm{Cu}$ NWs, promoting the electro-oxidation of AA. This was further confirmed in a comparison test in Figure $2 \mathrm{C}$. When AA was added to PBS, an anodic peak at $-0.08 \mathrm{~V}$ was observed (curve b). After the 
addition of $\mathrm{AC}$, one more peak at $+0.38 \mathrm{~V}$ appeared (curve c). An anodic peak at $+0.16 \mathrm{~V}$ was due to the DA oxidation (curve d). The three well-defined separated anodic peaks detected from DPV approximately corresponding to the $\mathrm{CV}$ results demonstrated the possibility for simultaneous testing of AA, DA, and AC on Nafion/Cu NWs-GO/GCE.
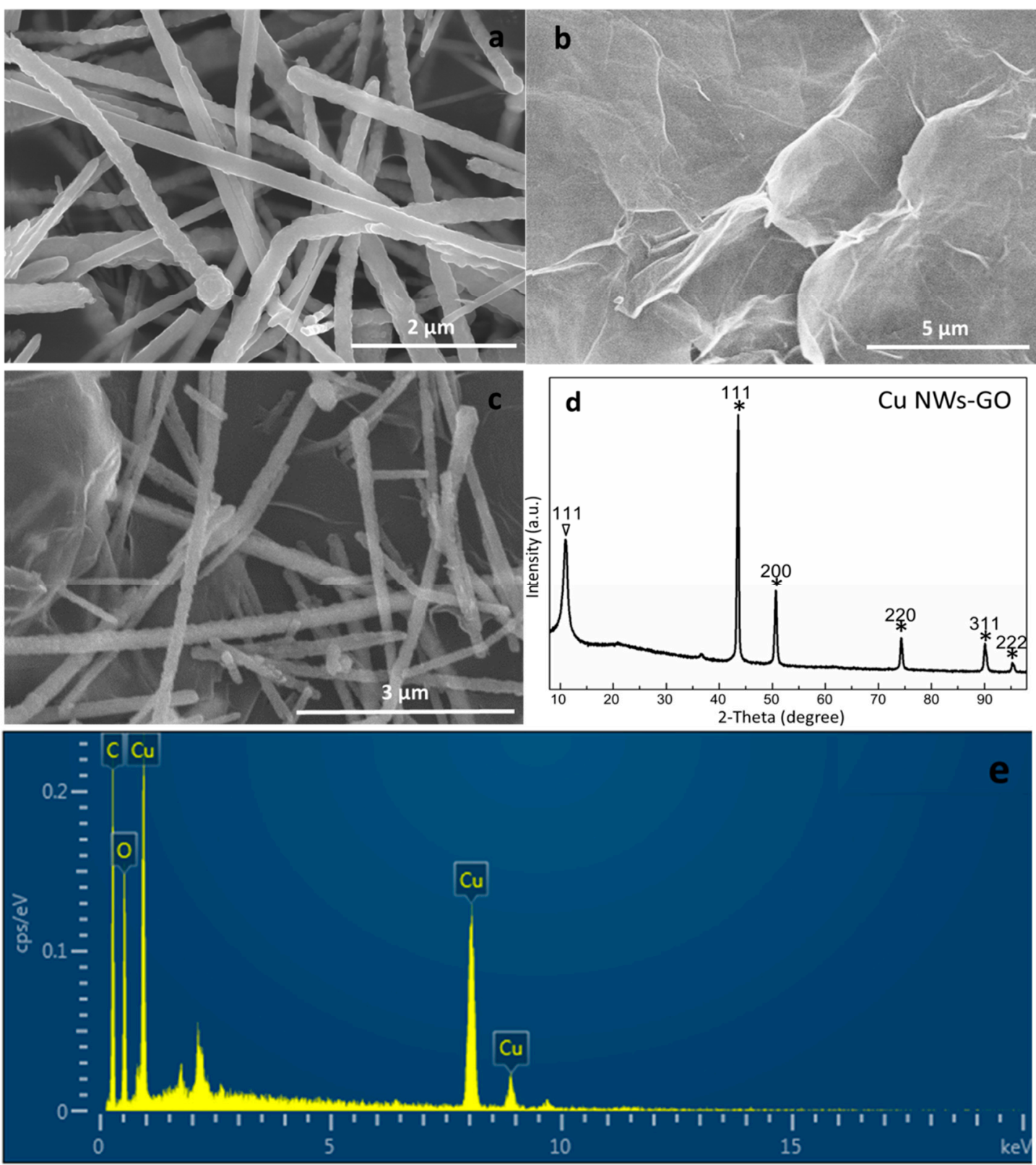

Figure 1. The scanning electron microscope (SEM) images of (a) copper nanowires (Cu NWs), (b) graphene oxide (GO) and (c) Cu NWs-GO nanocomposite. (d) The X-ray diffraction (XRD) patterns of $\mathrm{Cu}$ NWs-GO nanocomposite. The asterisks represent the $2 \theta$ values of $\mathrm{Cu}$ NWs surface. (e) The energy-dispersive $\mathrm{X}$-ray (EDS) spectrum of $\mathrm{Cu}$ NWs-GO nanocomposite. 

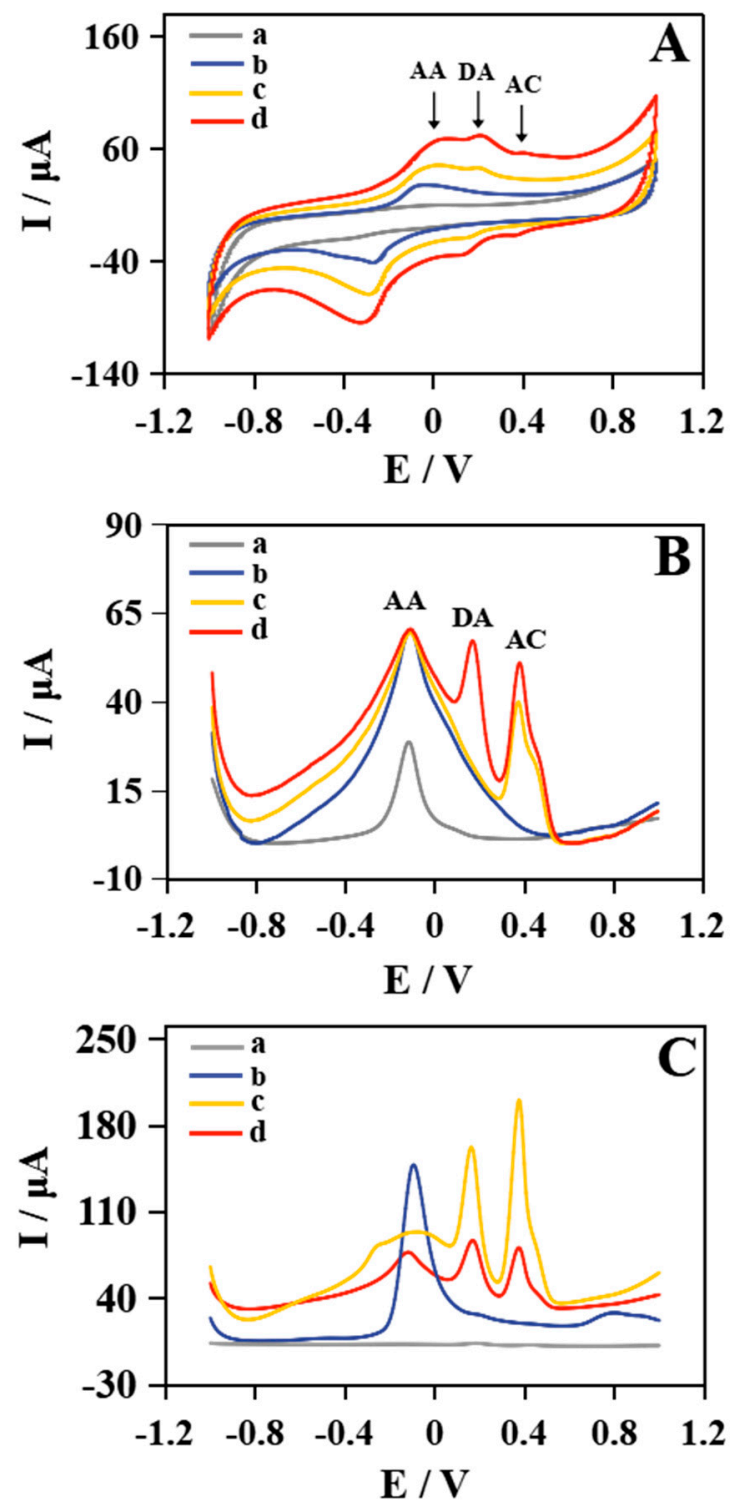

Figure 2. (A) Cyclic voltammetry (CV) of the Nafion/Cu NWs-GO/GCE with: (a) $0 \mu \mathrm{M}$ ascorbic acid (AA), $0 \mu \mathrm{M}$ dopamine (DA) and $0 \mu \mathrm{M}$ acetaminophen (AC), (b) $10 \mu \mathrm{M} \mathrm{AA}, 0 \mu \mathrm{M}$ DA and $0 \mu \mathrm{M} \mathrm{AC}$, (c) $10 \mu \mathrm{M}$ AA, $50 \mu \mathrm{M}$ DA and $0 \mu \mathrm{M}$ AC, and (d) $10 \mu \mathrm{M}$ AA, $50 \mu \mathrm{M}$ DA and $50 \mu \mathrm{M}$ AC. (B) Differential pulse voltammetry (DPV) of the Nafion/Cu NWs-GO/GCE with: (a) $0 \mu \mathrm{M}$ AA, $0 \mu \mathrm{M}$ DA and $0 \mu \mathrm{M} \mathrm{AC}$, (b) $10 \mu \mathrm{M}$ AA, $0 \mu \mathrm{M}$ DA and $0 \mu \mathrm{M} \mathrm{AC}$, (c) $10 \mu \mathrm{M} \mathrm{AA}, 0 \mu \mathrm{M}$ DA and $50 \mu \mathrm{M}$ AC, and (d) $10 \mu \mathrm{M} \mathrm{AA}$, $50 \mu \mathrm{M}$ DA and $50 \mu \mathrm{M}$ AC. (C) DPVs of (a) Nafion/GCE, (b) Nafion/Cu NWs/GCE, (c) Nafion/GO/GCE and (d) Nafion/Cu NWs-GO/GCE in 0.1 M phosphate-buffered saline (PBS) (pH 7.0) containing $10 \mu \mathrm{M}$ AA, $50 \mu \mathrm{M}$ DA, and $50 \mu \mathrm{M}$ AC.

The voltammetric responses of different electrodes were compared as well to further prove the function of Nafion/Cu NWs-GO/GCE. Figure 2C displays the DPVs of the ternary mixture of $10 \mu \mathrm{M}$ AA, $50 \mu \mathrm{M}$ DA, and $50 \mu \mathrm{M}$ AC in $0.1 \mathrm{M}$ PBS (pH 7.0) at (a) Nafion/GCE, (b) Nafion/Cu NWs/GCE, (c) Nafion/GO/GCE, and (d) Nafion/Cu NWs-GO/GCE. No voltammetric peaks of AA, DA, and AC appeared on Nafion/GCE. For Nafion/Cu NWs/GCE, a strong voltammetric response appears around $-0.08 \mathrm{~V}$, consistent with the potential of AA oxidation peak, indicating the higher electrochemical activity of $\mathrm{Cu}$ NWs for AA. In addition, two sharp oxidation peaks occur at $+0.16 \mathrm{~V}$ and $+0.38 \mathrm{~V}$, which are in accordance with those of DA and AC observed on Nafion/GO/GCE, respectively. However, a less distinct outline oxidation peak of AA around $-0.08 \mathrm{~V}$ is indeterminacy of Nafion/GO/GCE. As 
expected, only the Nafion/Cu NWs-GO/GCE simultaneously shows three well-defined oxidation peaks at potentials of $-0.08 \mathrm{~V},+0.16 \mathrm{~V}$, and $+0.38 \mathrm{~V}$. The above results show that Nafion/Cu NWs-GO/GCE shows a concurrently improved electrochemical activity for AA, DA, and AC. This may be due to the superiority of the prepared nanomaterials' combined different functions within $\mathrm{Cu}$ NWs and GO. First, GO is rich in carboxylic acid, epoxy, phenol and hydroxyl groups on its basal planes and edges, giving GO the capability of adsorption and intercalation of electroactive species through hydrogen bonds, such as the proton-donating group of AA, DA, and AC [9]. Second, other than the GO serving as a site for a prominent electron acceptor, the modified electrochemical activity is attributed to the $\mathrm{Cu} N W$ s located on GO notably enlarging the specific electrochemical active areas and facilitating electron transfer rate, which can be conducive to electro-oxidation of AA, DA, and AC on the surface of a modified electrode. Third, the $\mathrm{Cu}$ NWs with superior electrochemical activity and outstanding conductivity capacitates this modified electrode to acquire a higher signal of electrochemical AA, as well as the effective separation of the three species. In consequence, the $\mathrm{Cu}$ NWs-GO nanocomposite-modified GCE exhibits a synergistic action for the simultaneous oxidation of AA, DA, and AC by combining and coordinating functions within $\mathrm{Cu}$ NWs and GO.

\subsection{Optimization of Detection Conditions}

The simultaneous test signal of the Nafion/Cu NWs-GO/GCE towards AA, DA, and AC is affected by certain parameters, including the composition ratio of the $\mathrm{Cu}$ NWs and GO, the amount of nanocomposite loaded on the electrode, and the $\mathrm{pH}$ of the working electrolyte. Thus, experiments were carried out to estimate the impact of these parameters. In Figure 3a, the current response of $\mathrm{AA}$ is higher, with an increasing ratio of $\mathrm{Cu} N W$ s during the ratio of $1: 1,2: 1$, and 3:1 (v/v). This is further proved by the fact that $\mathrm{Cu}$ NWs have a good electrochemical oxidation effect with AA. Because of the larger ratio of GO, the current response of DA and AC increases progressively. As the results demonstrate, the ratio of $\mathrm{Cu}$ NWs to GO of 1:4 simultaneously reaches the maximum signal for the three analytes. With the optimal ratio, the loading amount of $\mathrm{Cu}$ NWs-GO nanocomposite was evaluated. Figure $3 b$ shows that the current responses of the three compounds increase to a plateau at $6 \mu \mathrm{L} \mathrm{Cu} \mathrm{NWs-GO} \mathrm{nanocomposite} \mathrm{loading} \mathrm{followed} \mathrm{by} \mathrm{a} \mathrm{sharp} \mathrm{decrease.} \mathrm{Therefore,} \mathrm{the} \mathrm{ratio} \mathrm{of} \mathrm{Cu}$ NWs to GO of 1:4 and $6 \mu \mathrm{L}$ nanocomposites loading is selected for the following tests. Figure $3 \mathrm{c}$ and $\mathrm{d}$ present the $\mathrm{pH}$ influence on the simultaneous response to the three analytes in $0.1 \mathrm{M}$ PBS containing $100 \mu \mathrm{M}$ AA, $400 \mu \mathrm{M}$ DA and $200 \mu \mathrm{M}$ AC. As shown in Figure 3c, the peak currents of DA and AC increment with the increase of $\mathrm{pH}$ from 3.0 to 7.0 followed by a gradual saturation from 7.0 to 8.0. In the case of $\mathrm{AA}$, the current signal initially decreases with $\mathrm{pH} \leq 5$ and then increases to reach a maximum of $\mathrm{pH}$ 8.0. Figure $3 \mathrm{~d}$ shows that the three oxidation peak potentials from AA, DA and AC are shifted negatively by increasing $\mathrm{pH}$, demonstrating that lower anodic potentials can distinguish the three molecules as well [9]. Therefore, $\mathrm{pH}$ 7.0, which is close to human physiological applications, was applied for subsequent work. In addition, the redox peak currents increases with varying scan rates from $40 \mathrm{mV} \mathrm{s}^{-1}$ to $240 \mathrm{mV} \mathrm{s}^{-1}$ (Figure S2). Good linear relationships between the peak currents and scan rates indicate that the electrooxidation of AA, DA, and AC on $\mathrm{Cu}$ NWs-GO nanocomposite modified GCE is a surface-controlled process. 

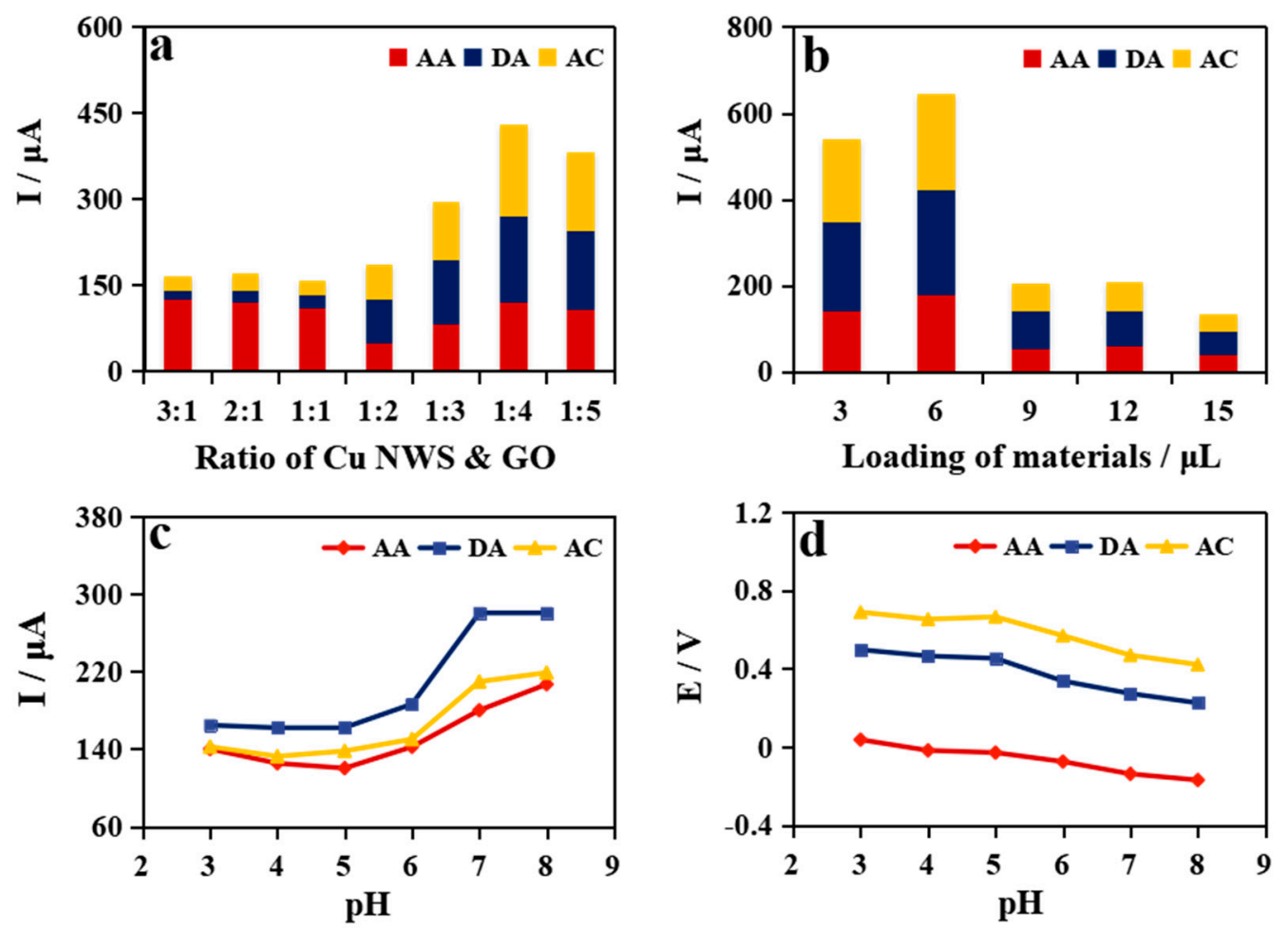

Figure 3. Optimum experiments of (a) the effect of the ratio of $\mathrm{Cu} N W s$ and GO, and (b) the loading of nanocomposite. Effect of $\mathrm{pH}$ on (c) peak current and (d) peak potential for the oxidation of $100 \mu \mathrm{M} \mathrm{AA}$, $400 \mu \mathrm{M}$ DA, $200 \mu \mathrm{M}$ AC in $0.1 \mathrm{M}$ PBS by DPV.

2.4. Simultaneous Detection of Ascorbic Acid (AA), Dopamine (DA), and Acetaminophen (AC) in Nafion/Cu NWs-GO/GCE

Under optimal conditions, the individual detections of AA, DA, and AC were first performed in $0.1 \mathrm{M}$ PBS ( $\mathrm{pH} 7.0$ ) by DPV (Figure S3a-c). Their approximate peak potentials are $-0.1 \mathrm{~V},+0.16 \mathrm{~V}$, and $+0.38 \mathrm{~V}$, respectively. The peak current responses of the three compounds increase with the increment of their concentrations. Figure S3d-f show the calibration plots for the DPV responses of AA, DA, and $\mathrm{AC}$ in the ranges from $1 \mu \mathrm{M}$ to $86 \mu \mathrm{M}\left(\mathrm{I}(\mathrm{AA})=1.0952 \times \mathrm{C}(\mathrm{AA})+74.559, \mathrm{R}^{2}=0.9674\right), 1 \mu \mathrm{M}$ to $120 \mu \mathrm{M}$ $\left(\mathrm{I}(\mathrm{DA})=0.8814 \times \mathrm{C}(\mathrm{DA})+3.5879, \mathrm{R}^{2}=0.9794\right)$, and $1 \mu \mathrm{M}$ to $90 \mu \mathrm{M}(\mathrm{I}(\mathrm{AC})=1.9479 \times \mathrm{C}(\mathrm{AC})+11.304$, $\left.\mathrm{R}^{2}=0.9883\right)$, respectively. The detection limits are calculated to be $0.44 \mu \mathrm{M}, 0.07 \mu \mathrm{M}$ and $0.19 \mu \mathrm{M}$ $(\mathrm{S} / \mathrm{N}=3)$, respectively. These results indicate that the excellent electrochemical activity of $\mathrm{Cu}$ NWs-GO nanocomposite provides a possible foundation for individual detection of AA, DA, and AC.

Next, the concentration of one target analyte that was only changed in the mixture was investigated on the basis that the concentrations of the other two analytes were kept constant. As shown in Figure S4a, three peaks located at $-0.1 \mathrm{~V},+0.16 \mathrm{~V}$ and $+0.38 \mathrm{~V}$, corresponding to the oxidation of AA, DA, and AC, are well separated in Nafion/Cu NWs-GO/GCE. The peak current of AA oxidation increases linearly in the range of $1-60 \mu \mathrm{M}$ with the detection limit of $0.11 \mu \mathrm{M}$ in the presence of $10 \mu \mathrm{M}$ DA and $10 \mu \mathrm{M}$ AC, which does not affect the peak potentials of DA and AC. The linear function of AA is $\mathrm{I}(\mathrm{AA})=1.7439 \times \mathrm{C}(\mathrm{AA})+104.79\left(\mathrm{R}^{2}=0.9604\right)($ Figure S4d). Figure S4b describes the representative oxidation current response variation with different DA concentrations between $1 \mu \mathrm{M}$ to $160 \mu \mathrm{M}$ and constant concentrations of AA $(10 \mu \mathrm{M})$ and AC $(10 \mu \mathrm{M})$. Figure S4e exhibits two linear regions from $10 \mu \mathrm{M}$ to $80 \mu \mathrm{M}\left(\mathrm{I}(\mathrm{DA}) 1=2.1328 \times \mathrm{C}(\mathrm{DA})+31.616, \mathrm{R}^{2}=0.998\right)$ and from $80 \mu \mathrm{M}$ to $160 \mu \mathrm{M}$ $\left(I(D A) 2=0.6041 \times C(D A)+154.13, R^{2}=0.9851\right)$, respectively. And the detection limit is $0.39 \mu \mathrm{M}$. Similarly, the current signal of AC increases with the increment of its corresponding concentrations between $1 \mu \mathrm{M}$ to $110 \mu \mathrm{M}$ under constant concentrations of AA $(10 \mu \mathrm{M})$ and DA $(10 \mu \mathrm{M})$ in Figure S4c,f. The corresponding linear equation is $\mathrm{I}(\mathrm{AC})=0.6008 \times \mathrm{C}(\mathrm{AC})+12.387\left(\mathrm{R}^{2}=0.9917\right)$, with a detection 
limit of $0.07 \mu \mathrm{M}$. These experimental results illustrate a possible synergy between $\mathrm{Cu}$ NWs and GO to simultaneously detect the three biomolecules.

As a consequence, the simultaneous testing of $\mathrm{AA}, \mathrm{DA}$, and $\mathrm{AC}$ was implemented by voltammetric methods by synchronously and orderly changing the concentrations from low to high of the three biomolecules. It is obvious from Figure $4 \mathrm{a}$ that the three oxidation peaks are non-overlapping and well separated, and the peak currents increase with the successive addition of AA, DA, and AC in greater concentrations. The corresponding calibration plots are presented in Figure $4 \mathrm{~b}$, which are linear in the concentration ranges of 1-60 $\mu \mathrm{M}, 1-100 \mu \mathrm{M}$, and 1-100 $\mu \mathrm{M}$ for AA, DA, and AC with detection limits of $0.05 \mu \mathrm{M}, 0.41 \mu \mathrm{M}$ and $0.04 \mu \mathrm{M}(\mathrm{S} / \mathrm{N}=3)$, respectively. The corresponding fitting equations of AA, DA, and AC are calculated as $\mathrm{I}(\mathrm{AA})=2.5523 \times \mathrm{C}(\mathrm{AA})+24.484\left(\mathrm{R}^{2}=0.9939\right), \mathrm{I}(\mathrm{DA})=2.0433 \times$ $C(D A)+7.9269\left(R^{2}=0.9961\right)$, and $I(A C)=1.5651 \times C(A C)+7.6101\left(R^{2}=0.996\right)$, respectively. The results demonstrate that the simultaneous discrimination of the three biomolecules in $\mathrm{Cu}$ NWs-GO composite is practicable in a mixture solution via DPV, and with wider linear ranges and/or lower detection limits than previously reported other nanomaterial modified electrodes (listed in Table 1), demonstrating that simultaneous testing of the three biomolecules can be performed successfully on Nafion/Cu NWs-GO/GCE with high sensitivity.
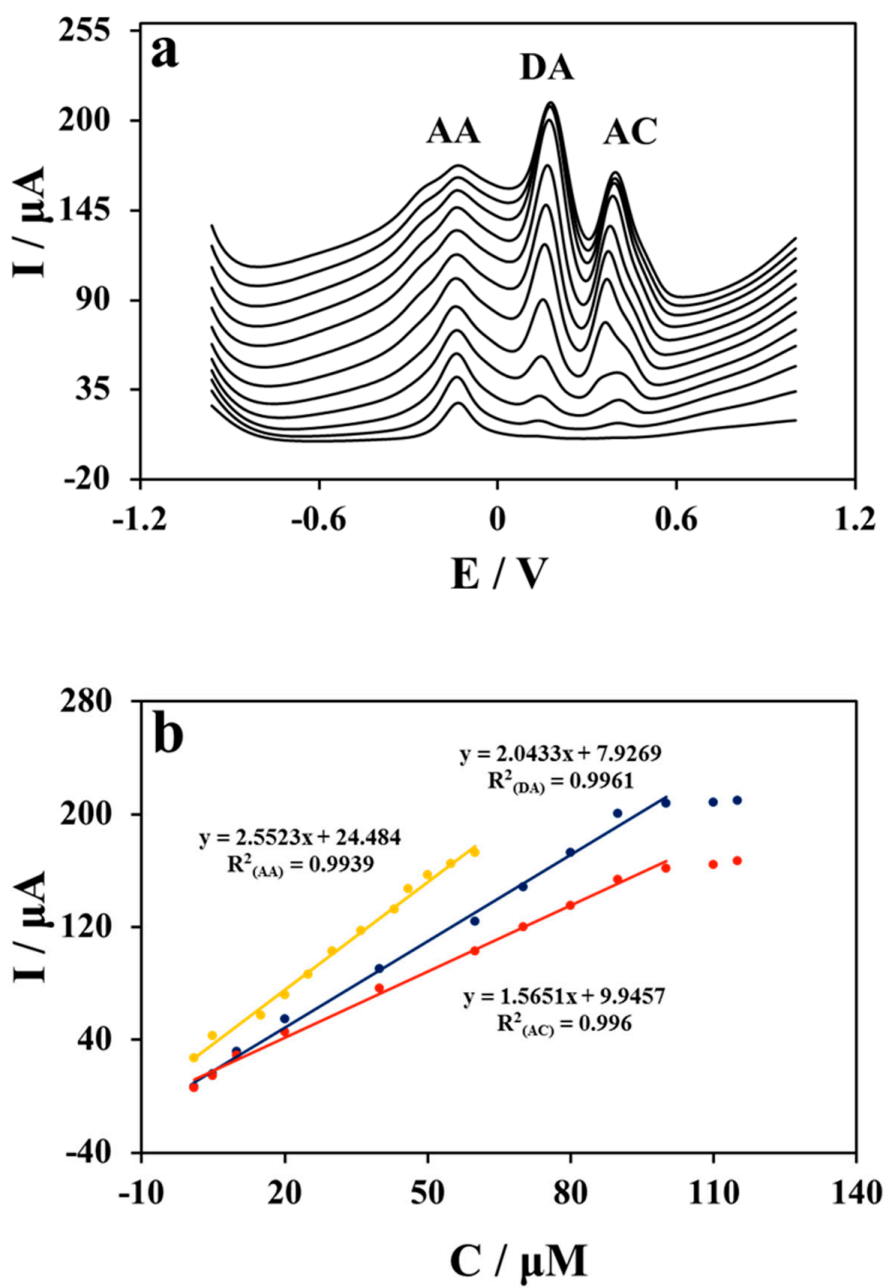

Figure 4. (a) DPV profiles at Nafion/Cu NWs-GO/GCE in 0.1 M PBS (pH 7.0) containing different concentrations of AA, DA, and AC. From bottom to up the concentrations: 1, 5, 15, 20, 25, 30, 36, 43, 46, $50,55,60 \mu \mathrm{M}$ for AA; 1, 5, 10, 20, 40, 60, 70, 80, 90, 100, 110, $115 \mu \mathrm{M}$ for DA; 1, 5, 10, 20, 40, 60, 70, 80, 90, $100,110,115 \mu \mathrm{M}$ for AC. (b) Plots of the oxidation peak currents of AA, DA and AC vs. concentrations. 
Table 1. Comparison of different electrodes for the responses of $\mathrm{AA}, \mathrm{DA}$, and $\mathrm{AC}$ at room temperature.

\begin{tabular}{|c|c|c|c|c|c|c|c|c|}
\hline \multirow{2}{*}{ Electrodes } & \multirow{2}{*}{ Methods } & \multicolumn{3}{|c|}{ Linear Ranges $(\mu \mathrm{M})$} & \multicolumn{3}{|c|}{ Detection Limit $(\mu \mathrm{M})$} & \multirow{2}{*}{ Ref. } \\
\hline & & AA & DA & AC & AA & DA & AC & \\
\hline GO-XDA- $\mathrm{Mn}_{2} \mathrm{O}_{3} / \mathrm{GCE}$ & Chronoamperometric & $10-8000$ & - & $1-1000$ & 0.6 & - & 0.056 & [29] \\
\hline MWCNT/GO/AuNR/GCE & DPV & $1-8000$ & - & - & 0.087 & - & - & [24] \\
\hline GO-ZIF67/GCE & DPV & - & $0.2-80$ & - & - & 0.05 & - & [28] \\
\hline $\mathrm{p}-\mathrm{GLY} / \mathrm{GO} / \mathrm{GCE}$ & DPV & - & $0.2-62$ & - & - & 0.011 & - & [31] \\
\hline AgNPs/P(Arg)-GO/GCE & DPV & $\begin{array}{c}4-2400 \\
\text { (only change } \\
\mathrm{C}_{\mathrm{AA}} \text { ) }\end{array}$ & $\begin{array}{c}0.05-50 \\
\text { (only } \\
\text { change } \\
\mathrm{C}_{\mathrm{DA}} \text { ) }\end{array}$ & - & 0.984 & 0.01 & - & [30] \\
\hline $\mathrm{Cu}_{2} \mathrm{O} / \mathrm{GR} / \mathrm{GCE}$ & DPV & - & - & $0.02-1.3$ & - & - & 0.0067 & [42] \\
\hline CuZEA/RGO/GCE & DPV & $\begin{array}{c}20-200 \\
\text { (only change } \\
\mathrm{C}_{\mathrm{AA}} \text { ) }\end{array}$ & $\begin{array}{c}0.1-19 \\
\text { (only } \\
\text { change } \\
\mathrm{C}_{\mathrm{DA}} \text { ) }\end{array}$ & - & 11 & 0.041 & - & [43] \\
\hline Zn-NiAl LDH/rGO/GCE & DPV & $0.5-11$ & $0.001-1$ & - & 0.0135 & 0.0001 & - & [44] \\
\hline $3 \mathrm{D}-\mathrm{MoS}_{2} / \mathrm{rGO} / \mathrm{Au} / \mathrm{GCE}$ & DPV & $2-5400$ & $0.3-198.3$ & - & 1.46 & 0.15 & - & [23] \\
\hline RGO-CdSe QD/GCE & DPV & $\begin{array}{c}\text { 390-1000 } \\
\text { (only change } \\
\mathrm{C}_{\mathrm{AA}} \text { ) }\end{array}$ & $\begin{array}{c}4.9-74 \\
\text { (only } \\
\text { change } \\
\mathrm{C}_{\mathrm{DA}} \text { ) }\end{array}$ & - & 66 & 0.11 & - & [45] \\
\hline $\begin{array}{c}\text { Fc-S-Au/C } \\
\text { NC/graphene/GCE }\end{array}$ & DPV & $8-400$ & $0.2-2.5$ & $0.5-46$ & 1.0 & 0.05 & 0.1 & [17] \\
\hline $\mathrm{Cu}^{2+} @ P D A-M W C N T s / G C E$ & DPV & 5-175 & $4-125$ & $5-75$ & 0.82 & 0.45 & 0.87 & [46] \\
\hline $\mathrm{Fe}_{3} \mathrm{O}_{4} @ \mathrm{Au}-\mathrm{S}-\mathrm{Fc} / \mathrm{GS}$-chitosan/GCE & DPV & $6-350$ & $0.5-50$ & $0.4-32$ & 1.0 & 0.1 & 0.05 & [16] \\
\hline PSNSB/CPE & DPV & $2.5-1050$ & $0.05-120$ & $0.033-158$ & 0.02 & 0.002 & 0.005 & [22] \\
\hline $\begin{array}{l}\mathrm{Au} / \mathrm{ZnO} / \mathrm{N}-\text { doped } \\
\text { graphene/GCE }\end{array}$ & DPV & $\begin{array}{c}30-13,000 \\
\text { (only change } \\
\mathrm{C}_{\mathrm{AA}} \text { ) }\end{array}$ & $\begin{array}{c}2-180 \\
\text { (only } \\
\text { change } \\
C_{D A} \text { ) }\end{array}$ & $\begin{array}{c}\text { 5-3100 } \\
\text { (only } \\
\text { change } \\
\mathrm{C}_{\mathrm{AC}} \text { ) }\end{array}$ & 5.0 & 0.4 & 0.8 & [1] \\
\hline $\mathrm{Cu}$ NWs/GO/GCE & DPV & $1-60$ & $1-100$ & $1-100$ & 0.05 & 0.41 & 0.04 & this work \\
\hline
\end{tabular}

\subsection{Interference, Reproducibility and Stability}

Glucose, chloride ion, sodium ion, and potassium ion, which exist abundantly in human blood, are commonly considered to impose a major issue on simultaneous detection of AA, DA, and AC [44,47-49]. In addition, uric acid, an endogenous reducing compound, is in co-existence with AA and DA in physiological conditions, which is considered to be the major interfering specie for the simultaneous detected sensors, especially including DA sensing, due to their closer oxidation potential $[47,50]$. Therefore, the selectivity of the as-prepared Nafion/Cu NWs-GO/GCE against the four interfering substances was examined. The normal physiological concentration of glucose is about $3-8 \mathrm{mM}$ in human blood and the normal level of AA and UA are about $0.1 \mathrm{mM}$ [48]. The presence of the optimum level of DA is $26-40 \mathrm{nM}$ under the physiological condition [51]. Referring to the similar studies measured the concentrations of inorganic ions [22,46], a challenging selectivity study was conducted using high concentration of glucose $(10 \mathrm{mM}), \mathrm{UA}(20 \mu \mathrm{M}), \mathrm{KCl}(1 \mathrm{mM})$, and $\mathrm{NaCl}(1 \mathrm{mM})$ compared to AA $(1 \mu \mathrm{M})$, DA $(1 \mu \mathrm{M})$, and AC $(1 \mu \mathrm{M})$. The selectivity experiment was evaluated by simultaneous addition of the four interference compounds to $0.1 \mathrm{M}$ PBS in the presence of AA, DA, and AC through DPV. It is found in Figure S5 that 10,000-fold glucose, 20-fold UA, and 1000-fold $\mathrm{Na}^{+}, \mathrm{K}^{+}$, and $\mathrm{Cl}^{-}$do not significantly interfere with the determination of AA, DA, and AC. The results demonstrate that the simultaneous determination of AA, DA, and AC were reliable via DPV, and with better selectivity than previously reported the other nanomaterials modified electrodes (listed in Table S1) [22,46], indicating that simultaneous testing of the three biomolecules can be successfully performed on Nafion/Cu NWs-GO/GCE.

Reproducibility was examined by analysis in a mixture of $30 \mu \mathrm{M} \mathrm{AA}, 45 \mu \mathrm{M}$ DA, and $45 \mu \mathrm{M}$ AC in 0.1 M PBS (pH 7.0) solution, applying five electrodes under the same modified conditions (Figure 5). The low relative standard deviations (RSD) of $2.4 \%, 2 \%$ and $2.5 \%$ for AA, DA, and AC, respectively, demonstrate good reproducibility of the prepared electrodes. Furthermore, the stability of the prepared working electrode was investigated for 12 days' storage in ultrapure water at $4{ }^{\circ} \mathrm{C}$. Before and after storage, the response signals of AA, DA, and AC decreased by $5.4 \%, 2.1 \%$, and $4.1 \%$ of their original current, respectively, demonstrating the good stability of the developed method. 


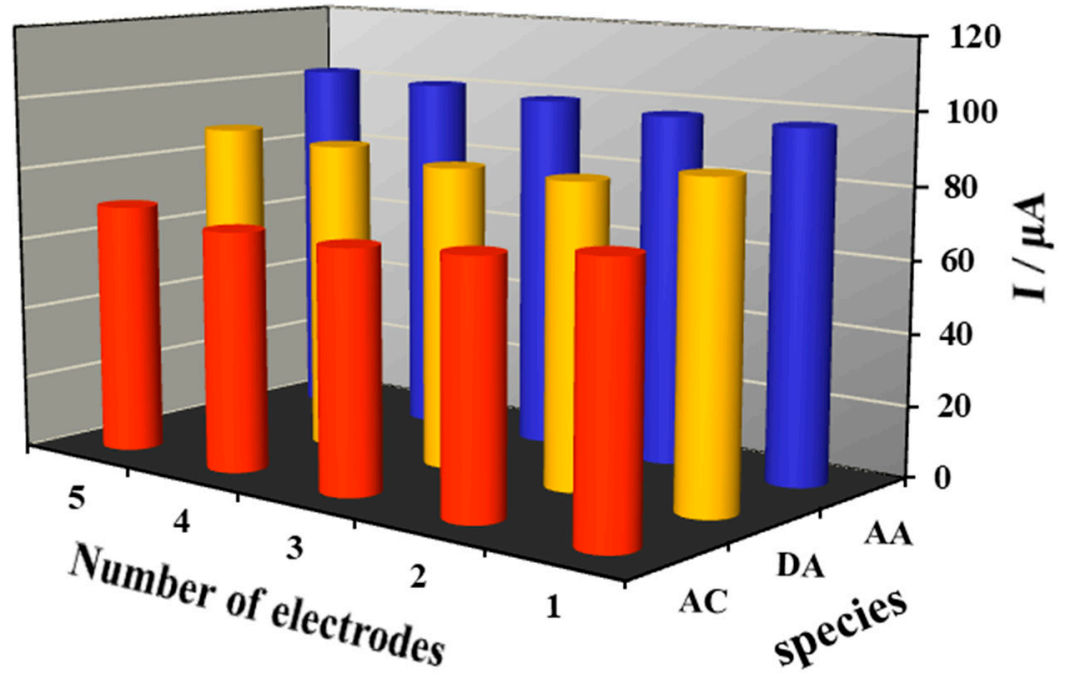

Figure 5. Reproducibility studies of a series of 5 electrodes with $30 \mu \mathrm{M}$ AA, $45 \mu \mathrm{M}$ DA, $45 \mu \mathrm{M}$ AC using DPV in 0.1 M PBS (pH 7.0) solution.

\subsection{Detection Application in Human Serum Sample}

Nafion/Cu NWs-GO/GCE was employed to simultaneously determine AA, DA, and AC in human serum samples with the standard addition method. The human serum samples were pretreated by centrifugation at $6000 \mathrm{rpm}$ for $5 \mathrm{~min}$, and the collected supernatants were diluted 100 times with $0.1 \mathrm{M}$ PBS (pH 7.0). The measured concentrations were calculated by the calibration plots shown in Figure $4 \mathrm{~b}$. As is seen in Table 2, the appropriate recoveries in the range of $94.6-101.7 \%$, and small RSD ranges between $0.6 \%$ and $3.3 \%$, indicate the reliability of $\mathrm{Cu}$ NWs-GO nanocomposite in the application of simultaneous testing of AA, DA, and AC in human serum samples.

Table 2. The simultaneous determination of AA, DA, and AC in human serum samples.

\begin{tabular}{|c|c|c|c|c|c|c|c|c|c|c|c|c|}
\hline \multirow[t]{2}{*}{ Samples } & \multicolumn{3}{|c|}{ Added $(\mu \mathrm{M})$} & \multicolumn{3}{|c|}{ Found $(\mu \mathrm{M})$} & \multicolumn{3}{|c|}{ Recoveries } & \multicolumn{3}{|c|}{$\begin{array}{l}\text { Relative Standard Deviation } \\
\text { (RSD) }(\%)(\mathrm{n}=5)\end{array}$} \\
\hline & AA & DA & AC & AA & DA & $\mathrm{AC}$ & AA & DA & AC & AA & DA & AC \\
\hline 1 & 50.0 & 68.0 & 70.0 & 49.1 & 66.9 & 71.2 & 98.2 & 98.4 & 101.7 & 3.3 & 1.9 & 2.1 \\
\hline 2 & 52.0 & 72.0 & 75.0 & 50.3 & 68.0 & 71.0 & 96.8 & 94.6 & 94.7 & 1.6 & 0.8 & 1.4 \\
\hline 3 & 54.0 & 74.0 & 78.0 & 51.8 & 70.1 & 73.8 & 96.0 & 94.8 & 94.6 & 1.0 & 0.6 & 0.8 \\
\hline
\end{tabular}

\section{Experiment}

\subsection{Reagents and Materials}

Uric acid, ascorbic acid, dopamine hydrochloride, copper(II) nitrate hemipentahydrate $\left(\mathrm{Cu}\left(\mathrm{NO}_{3}\right)_{2} \bullet 2.5 \mathrm{H}_{2} \mathrm{O}\right)$, ethylenediamine $(>99.9 \%)$, Nafion 117 solution, hydrazine, sodium hydroxide and glucose were purchased from Sigma-Aldrich (St. Louis, MO, USA). Acetaminophen was purchased from Alfa Aesar (Heysham, England). Graphene oxide was obtained from XFNANO Nanotechnology Co., Ltd. (Nanjing, Jiangsu, China), which is also the manufacturer of GO. Disodium hydrogen phosphate dodecahydrate, sodium chloride, potassium chloride, ethanol, acetone and sodium dihydrogen phosphate dehydrate were purchased from Chongqing Chuandong Chemical Group Co., Ltd. (Chongqing, China). Human serum samples were used as received from the First Affiliated Hospital of Chongqing Medical University. Ultrapure water $(18.2 \mathrm{M} \Omega \mathrm{cm})$ was applied for preparing all solutions. 


\subsection{Characterization and Electrochemical Measurements}

The microstructure characterizations of the prepared materials were accomplished on a SU8010 scanning electron microscope (SEM, Hitachi, Japan) which was equipped with $\mathrm{X}-\mathrm{Max}{ }^{\mathrm{N}}$ energy-dispersive X-ray spectroscopy (EDS, Oxford Instruments, UK). The crystal structures of the samples were carried out on an Empyrean X-ray Diffraction (XRD) System (Empyrean, PANalytical, Almelo, The Netherlands). All electrochemical tests were performed on a CHI 660D electrochemical workstation (Shanghai CH Instruments Co., Shanghai, China) and AUTOLAB PGSTAT302N (Metrohm Autolab, Herisau, Switzerland). A three-electrode system was commonly utilized with a 3-mm-diameter glassy carbon electrode as the working electrode, $\mathrm{Ag} / \mathrm{AgCl}(3 \mathrm{M} \mathrm{KCl})$ electrode as the reference electrode, and $\mathrm{Pt}$ wire as the counter electrode.

\subsection{Preparation of Nanocomposite Modified Electrode}

The commercial GO was dispersed in ultrapure water with sonication for $4 \mathrm{~h}$ to obtain homogenous dispersion. Copper NWs were prepared based on previous reports [25,33]. A mixed solution of $20 \mathrm{~mL} \mathrm{NaOH}$ solution $(15 \mathrm{M}), 1 \mathrm{~mL} \mathrm{Cu}\left(\mathrm{NO}_{3}\right)_{2} \bullet 2.5 \mathrm{H}_{2} \mathrm{O}(0.1 \mathrm{M}), 0.16 \mathrm{~mL}$ ethylenediamine and $25 \mu \mathrm{L}$ hydrazine $\left(35 \mathrm{wt} \%\right.$ ) was reacted at $60{ }^{\circ} \mathrm{C}$ for $2 \mathrm{~h}$. The $\mathrm{Cu}$ NWs end product was adequately washed with ethanol and ultrapure water, separately, and then dispersed in ethanol for further use. Next, a given volume ratio of $\mathrm{Cu}$ NWs $(2 \mathrm{mg} / \mathrm{mL})$ and GO $(2 \mathrm{mg} / \mathrm{mL})$ was mixed and sonicated for $5 \mathrm{~h}$ at room temperature to obtain uniform $\mathrm{Cu}$ NWs-GO nanocomposite suspension. An appropriate amount of Cu NWs-GO nanocomposite suspension was directly dropped on the surface of bare GCEs which were cleaned carefully with conventional polished processes with alumina slurries. Then, $20 \mu \mathrm{L}$ of Nafion ethanol solution $(0.1 \mathrm{wt} \%)$ was cast on the modified layer for the purpose of entrapment and long-term stability. After drying at room temperature, the modified electrode was readily prepared and denoted as Nafion/Cu NWs-GO/GCE. The control electrodes were also prepared in a similar way.

\section{Conclusions}

Copper NWs modified with GO nanosheets for simultaneous electrochemical analysis of AA, DA, and $\mathrm{AC}$ were investigated. The manufacture of $\mathrm{Cu}$ NWs-GO nanocomposite went through a simple sonication technique. It was successfully characterized by SEM, XRD, and EDS. The Cu NWs-GO nanocomposite with a Nafion-modified glassy carbon electrode exhibits three well-defined peaks from AA, DA, and AC. The electrochemical property studies verify the synergistic effect of Cu NWs and GO. The specific surface, electrochemical oxidation performance and conductivity of the nanocomposite are improved when compared to each individual component. The current responses of the prepared electrode for AA, DA, and AC are simultaneously changed regularly with a wide linear range and a low detection limit via DPV. The good reproducibility, selectivity, and stability demonstrate its outstanding applicability to simultaneous testing of AA, DA, and AC. The method successfully applied in human serum samples reveals that the $\mathrm{Cu}$ NWs-GO nanocomposite is a promising candidate for AA, DA and AC simultaneous detection.

Supplementary Materials: The following are available online. Figure S1. The XRD patterns of (a) GO and (b) Cu NWs; Figure S2. (a) Cyclic voltammograms of the Nafion/Cu NWs-GO/GCE in 0.1 M PBS (pH 7.0) containing $20 \mu \mathrm{M}$ AA, $50 \mu \mathrm{M}$ DA, and $50 \mu \mathrm{M}$ AC at different scan rates $(40-240 \mathrm{mV} \bullet \mathrm{s}-1)$ and the corresponding plots of current vs. scan rate of (b) AA, (c) DA, and (d) AC; Figure S3. DPVs of Nafion/Cu NWs-GO/GCE in 0.1 M PBS (pH 7.0) containing (a) AA: 1, 5, 10, 15, 20, 35, 45, 55, 60, 66, 72, 76, 80, 86 $\mu$ M; (b) DA: 1, 5, 10, 30, 40, 50, 60, 80, 100, $120 \mu \mathrm{M}$; and (c) AC: 1, 5, 10, 20, 40, 50, 80, 90, 100, $110 \mu \mathrm{M}$. The corresponding calibration plots of (d) AA, (e) DA, and (f) AC, respectively; Figure S4. DPVs at Nafion/Cu NWs-GO/GCE in 0.1 M PBS (pH 7.0); Figure S5. Interference test of Nafion/Cu NWs-GO/GCE upon the addition of different substances, DPVs with (a) $1 \mu \mathrm{M}$ AA, $1 \mu \mathrm{M}$ DA, $1 \mu \mathrm{M}$ AC and with (b) addition of $10 \mathrm{mM}$ glucose, $20 \mu \mathrm{M} \mathrm{UA}, 1 \mathrm{mM} \mathrm{NaCl}$ and $1 \mathrm{mM} \mathrm{KCl}$. Table S1. Comparison of different electrodes on selectivity study.

Author Contributions: Conceptualization, W.H., Y.Z. and G.Z.; Data curation, W.H. and Y.Z.; Formal analysis, W.H. and Y.Z.; Funding acquisition, Y.Z., H.L., Q.P. and G.Z.; Investigation, W.H., Y.Z., J.F., Q.S. and W.L.; Methodology, Y.Z. and J.F.; Project administration, G.Z.; Resources, J.F. and H.L.; Supervision, Y.Z. and G.Z.; Writing —original draft, W.H.; Writing—review \& editing, Y.Z. and G.Z. 
Funding: This work is supported by the Project of Science and Technology of Chongqing Yuzhong District (20170119, 20180112), the National Project of University Students Innovation and Entrepreneurship Training Program (201810631001), the Project of Scientific Research and Innovative Experiment for College Student in Chongqing Medical University (CXSY201803), the Project of Tutorial System of Medical Undergraduate in Lab Teaching \& Management Center in Chongqing Medical University (LTMCMTS201807), the Natural Science Foundation of Chongqing (cstc2017jcyjAX0113).

Conflicts of Interest: The authors declare no conflict of interest.

\section{References}

1. Chen, X.; Zhang, G.; Shi, L.; Pan, S.; Liu, W.; Pan, H. Au/ZnO hybrid nanocatalysts impregnated in N-doped graphene for simultaneous determination of ascorbic acid, acetaminophen and dopamine. Mater. Sci. Eng. C 2016, 65, 80-89. [CrossRef] [PubMed]

2. Zhao, D.; Yu, G.; Tian, K.; Xu, C. A highly sensitive and stable electrochemical sensor for simultaneous detection towards ascorbic acid, dopamine, and uric acid based on the hierarchical nanoporous PtTi alloy. Biosens. Bioelectron. 2016, 82, 119-126. [CrossRef] [PubMed]

3. Madrakian, T.; Haghshenas, E.; Afkhami, A. Simultaneous determination of tyrosine, acetaminophen and ascorbic acid using gold nanoparticles/multiwalled carbon nanotube/glassy carbon electrode by differential pulse voltammetric method. Sens. Actuators B Chem. 2014, 193, 451-460. [CrossRef]

4. Wang, Q.; Liu, S.; Fu, L.; Cao, Z.; Ye, W.; Li, H.; Guo, P.; Zhao, X.S. Electrospun gamma-Fe $\mathrm{O}_{3}$ nanofibers as bioelectrochemical sensors for simultaneous determination of small biomolecules. Anal. Chim. Acta 2018, 1026, 125-132. [CrossRef] [PubMed]

5. Yang, Y.J.; Li, W. CTAB functionalized graphene oxide/multiwalled carbon nanotube composite modified electrode for the simultaneous determination of ascorbic acid, dopamine, uric acid and nitrite. Biosens. Bioelectron. 2014, 56, 300-306. [CrossRef] [PubMed]

6. Habibi, B.; Pournaghi-Azar, M.H. Simultaneous determination of ascorbic acid, dopamine and uric acid by use of a MWCNT modified carbon-ceramic electrode and differential pulse voltammetry. Electrochim. Acta 2010, 55, 5492-5498. [CrossRef]

7. Kim, S.-J.; Cho, Y.K.; Lee, C.; Kim, M.H.; Lee, Y. Real-time direct electrochemical sensing of ascorbic acid over rat liver tissues using $\mathrm{RuO}_{2}$ nanowires on electrospun $\mathrm{TiO}_{2}$ nanofibers. Biosens. Bioelectron. 2016, 77, 1144-1152. [CrossRef] [PubMed]

8. Zhang, X.; Yu, S.; He, W.; Uyama, H.; Xie, Q.; Zhang, L.; Yang, F. Electrochemical sensor based on carbon-supported $\mathrm{NiCoO}_{2}$ nanoparticles for selective detection of ascorbic acid. Biosens. Bioelectron. 2014, 55, 446-451. [CrossRef] [PubMed]

9. Liu, X.; Zhang, L.; Wei, S.; Chen, S.; Ou, X.; Lu, Q. Overoxidized polyimidazole/graphene oxide copolymer modified electrode for the simultaneous determination of ascorbic acid, dopamine, uric acid, guanine and adenine. Biosens. Bioelectron. 2014, 57, 232-238. [CrossRef]

10. Noroozifar, M. Solid-phase iodine as an oxidant in flow injection analysis: Determination of ascorbic acid in pharmaceuticals and foods by background correction. Talanta 2003, 61, 173-179. [CrossRef]

11. Alarcón-Ángeles, G.; Perez-Lopez, B.; Palomar-Pardavé, M.; Ramírez-Silva, M.; Alegret, S.; Merkoçi, A. Enhanced host-guest electrochemical recognition of dopamine using cyclodextrin in the presence of carbon nanotubes. Carbon 2008, 46, 898-906. [CrossRef]

12. Damier, P.; Hirsch, E.C.; Agid, Y.; Graybiel, A.M. The substantia nigra of the human brain. II. Patterns of loss of dopamine-containing neurons in Parkinson's disease. Brain 1999, 122, 1437-1448. [CrossRef] [PubMed]

13. El-Said, W.A.; Lee, J.-H.; Oh, B.-K.; Choi, J.-W. 3-D nanoporous gold thin film for the simultaneous electrochemical determination of dopamine and ascorbic acid. Electrochem. Commun. 2010, 12, 1756-1759. [CrossRef]

14. Yang, L.; Liu, D.; Huang, J.; You, T. Simultaneous determination of dopamine, ascorbic acid and uric acid at electrochemically reduced graphene oxide modified electrode. Sens. Actuators B Chem. 2014, 193, 166-172. [CrossRef]

15. Habibi, B.; Jahanbakhshi, M.; Pournaghi-Azar, M.H. Simultaneous determination of acetaminophen and dopamine using SWCNT modified carbon-ceramic electrode by differential pulse voltammetry. Electrochim. Acta 2011, 56, 2888-2894. [CrossRef] 
16. Liu, M.; Chen, Q.; Lai, C.; Zhang, Y.; Deng, J.; Li, H.; Yao, S. A double signal amplification platform for ultrasensitive and simultaneous detection of ascorbic acid, dopamine, uric acid and acetaminophen based on a nanocomposite of ferrocene thiolate stabilized $\mathrm{Fe}_{3} \mathrm{O}_{4} @ \mathrm{Au}$ nanoparticles with graphene sheet. Biosens. Bioelectron. 2013, 48, 75-81. [CrossRef] [PubMed]

17. Yang, L.; Huang, N.; Lu, Q.; Liu, M.; Li, H.; Zhang, Y.; Yao, S. A quadruplet electrochemical platform for ultrasensitive and simultaneous detection of ascorbic acid, dopamine, uric acid and acetaminophen based on a ferrocene derivative functional Au NPs/carbon dots nanocomposite and graphene. Anal. Chim. Acta 2016, 903, 69-80. [CrossRef]

18. Lian, X.; Huang, Y.; Zhu, Y.; Fang, Y.; Zhao, R.; Joseph, E.; Li, J.; Pellois, J.-P.; Zhou, H. Long-Persistent Enzyme-MOF Nanoreactor Activates Non-toxic Paracetamol for Cancer Therapy. Angew. Chem. Int. Edit. 2018, 57, 5725-5730. [CrossRef]

19. Bui, M.-P.N.; Li, C.A.; Han, K.N.; Pham, X.-H.; Seong, G.H. Determination of acetaminophen by electrochemical co-deposition of glutamic acid and gold nanoparticles. Sens. Actuators B Chem. 2012, 174, 318-324. [CrossRef]

20. Lu, D.; Zhang, Y.; Wang, L.; Lin, S.; Wang, C.; Chen, X. Sensitive detection of acetaminophen based on $\mathrm{Fe}_{3} \mathrm{O}_{4}$ nanoparticles-coated poly(diallyldimethylammonium chloride)-functionalized graphene nanocomposite film. Talanta 2012, 88, 181-186. [CrossRef]

21. Huang, J.; Liu, Y.; Hou, H.; You, T. Simultaneous electrochemical determination of dopamine, uric acid and ascorbic acid using palladium nanoparticle-loaded carbon nanofibers modified electrode. Biosens. Bioelectron. 2008, 24, 632-637. [CrossRef] [PubMed]

22. Soltani, N.; Tavakkoli, N.; Ahmadi, N.; Davar, F. Simultaneous determination of acetaminophen, dopamine and ascorbic acid using a PbS nanoparticles Schiff base-modified carbon paste electrode. Comptes Rendus Chimie 2015, 18, 438-448. [CrossRef]

23. Zhao, Y.; Zhou, J.; Jia, Z.; Huo, D.; Liu, Q.; Zhong, D.; Hu, Y.; Yang, M.; Bian, M.; Hou, C. In-situ growth of gold nanoparticles on a 3D-network consisting of a MoS2/rGO nanocomposite for simultaneous voltammetric determination of ascorbic acid, dopamine and uric acid. Mikrochim. Acta 2019, 186, 92. [CrossRef] [PubMed]

24. Zhao, Y.; Qin, J.; Xu, H.; Gao, S.; Jiang, T.; Zhang, S.; Jin, J. Gold nanorods decorated with graphene oxide and multi-walled carbon nanotubes for trace level voltammetric determination of ascorbic acid. Mikrochim. Acta 2018, 186, 17. [CrossRef] [PubMed]

25. Zang, G.; Hao, W.; Li, X.; Huang, S.; Gan, J.; Luo, Z.; Zhang, Y. Copper nanowires-MOFs-graphene oxide hybrid nanocomposite targeting glucose electro-oxidation in neutral medium. Electrochim. Acta 2018, 277, 176-184. [CrossRef]

26. Dreyer, D.R.; Park, S.; Bielawski, C.W.; Ruoff, R.S. The chemistry of graphene oxide. Chem. Soc. Rev. 2010, 39, 228-240. [CrossRef] [PubMed]

27. Mkhoyan, K.A.; Contryman, A.W.; Silcox, J.; Stewart, D.A.; Eda, G.; Mattevi, C.; Miller, S.; Chhowalla, M. Atomic and Electronic Structure of Graphene-Oxide. Nano Lett. 2009, 9, 1058-1063. [CrossRef]

28. Tang, J.; Jiang, S.; Liu, Y.; Zheng, S.; Bai, L.; Guo, J.; Wang, J. Electrochemical determination of dopamine and uric acid using a glassy carbon electrode modified with a composite consisting of a Co(II)-based metalorganic framework (ZIF-67) and graphene oxide. Mikrochim. Acta 2018, 185, 486. [CrossRef]

29. Ejaz, A.; Jeon, S. A highly stable and sensitive GO-XDA- $\mathrm{Mn}_{2} \mathrm{O}_{3}$ electrochemical sensor for simultaneous electrooxidation of paracetamol and ascorbic acid. Electrochim. Acta 2017, 245, 742-751. [CrossRef]

30. Tı̆̆g, G.A. Development of electrochemical sensor for detection of ascorbic acid, dopamine, uric acid and l-tryptophan based on Ag nanoparticles and poly(l-arginine)-graphene oxide composite. J. Electroanal. Chem. 2017, 807, 19-28.

31. He, S.; He, P.; Zhang, X.; Zhang, X.; Liu, K.; Jia, L.; Dong, F. Poly(glycine)/graphene oxide modified glassy carbon electrode: Preparation, characterization and simultaneous electrochemical determination of dopamine, uric acid, guanine and adenine. Anal. Chim. Acta 2018, 1031, 75-82. [CrossRef] [PubMed]

32. Kholmanov, I.N.; Domingues, S.H.; Chou, H.; Wang, X.; Tan, C.; Kim, J.-Y.; Li, H.; Piner, R.; Zarbin, A.J.G.; Ruoff, R.S. Reduced Graphene Oxide/Copper Nanowire Hybrid Films as High-Performance Transparent Electrodes. ACS Nano 2013, 7, 1811-1816. [CrossRef] [PubMed]

33. Zhang, Y.; Su, L.; Manuzzi, D.; Monteros, H.V.E.D.L.; Jia, W.; Huo, D.; Hou, C.; Lei, Y. Ultrasensitive and selective non-enzymatic glucose detection using copper nanowires. Biosens. Bioelectron. 2012, 31, 426-432. [CrossRef] [PubMed] 
34. Krishnamoorthy, K.; Veerapandian, M.; Yun, K.; Kim, S.-J.; Veerapandian, D.M. The chemical and structural analysis of graphene oxide with different degrees of oxidation. Carbon 2013, 53, 38-49. [CrossRef]

35. Xu, J.; Wang, K.; Zu, S.-Z.; Han, B.-H.; Wei, Z. Hierarchical Nanocomposites of Polyaniline Nanowire Arrays on Graphene Oxide Sheets with Synergistic Effect for Energy Storage. ACS Nano 2010, 4, 5019-5026. [CrossRef]

36. Wu, C.; Chen, Z.; Wang, F.; Hu, Y.; Wang, E.; Rao, Z.; Zhang, X. In situ reduction of graphene oxide to improve the thermal and wettability properties of urea-melamine-modified phenol formaldehyde resin composites. Mater. Res. Express 2018, 6, 025302. [CrossRef]

37. Oko, D.N.; Garbarino, S.; Zhang, J.; Xu, Z.; Chaker, M.; Ma, D.; Guay, D.; Tavares, A.C. Dopamine and ascorbic acid electro-oxidation on $\mathrm{Au}, \mathrm{AuPt}$ and $\mathrm{Pt}$ nanoparticles prepared by pulse laser ablation in water. Electrochim. Acta 2015, 159, 174-183. [CrossRef]

38. Kim, S.-J.; Kim, Y.L.; Yu, A.; Lee, J.; Lee, S.C.; Lee, C.; Kim, M.H.; Lee, Y. Electrospun iridium oxide nanofibers for direct selective electrochemical detection of ascorbic acid. Sens. Actuators B Chem. 2014, 196, 480-488. [CrossRef]

39. Pisoschi, A.M.; Pop, A.; Serban, A.I.; Fafaneata, C. Electrochemical methods for ascorbic acid determination. Electrochim. Acta 2014, 121, 443-460. [CrossRef]

40. Li, B.; Zhou, Y.; Wu, W.; Liu, M.; Mei, S.; Zhou, Y.; Jing, T. Highly selective and sensitive determination of dopamine by the novel molecularly imprinted poly(nicotinamide)/CuO nanoparticles modified electrode. Biosens. Bioelectron. 2015, 67, 121-128. [CrossRef]

41. Bessems, J.G.M.; Vermeulen, N.P.E. Paracetamol (Acetaminophen)-Induced Toxicity: Molecular and Biochemical Mechanisms, Analogues and Protective Approaches. Crit. Rev. Toxicol. 2001, 31, 55-138. [CrossRef] [PubMed]

42. Yang, H.; Liu, B.; Ding, Y.; Li, L.; Ouyang, X. Fabrication of cuprous oxide nanoparticles-graphene nanocomposite for determination of acetaminophen. J. Electroanal. Chem. 2015, 757, 88-93. [CrossRef]

43. He, P.; Wang, W.; Du, L.; Dong, F.; Deng, Y.; Zhang, T. Zeolite A functionalized with copper nanoparticles and graphene oxide for simultaneous electrochemical determination of dopamine and ascorbic acid. Anal. Chim. Acta 2012, 739, 25-30. [CrossRef] [PubMed]

44. Asif, M.; Aziz, A.; Wang, H.; Wang, Z.; Wang, W.; Ajmal, M.; Xiao, F.; Chen, X.; Liu, H. Superlattice stacking by hybridizing layered double hydroxide nanosheets with layers of reduced graphene oxide for electrochemical simultaneous determination of dopamine, uric acid and ascorbic acid. Microchim. Acta 2019, 186, 61. [CrossRef] [PubMed]

45. Tavakolian, E.; Tashkhourian, J. Sonication-assisted preparation of a nanocomposite consisting of reduced graphene oxide and CdSe quantum dots, and its application to simultaneous voltammetric determination of ascorbic acid, dopamine and uric acid. Microchim. Acta 2018, 185, 456. [CrossRef] [PubMed]

46. Shahbakhsh, M.; Noroozifar, M. Copper polydopamine complex/multiwalled carbon nanotubes as novel modifier for simultaneous electrochemical determination of ascorbic acid, dopamine, acetaminophen, nitrite and xanthine. J. Solid State Electrochem. 2018, 22, 3049-3057. [CrossRef]

47. Liu, X.; Shangguan, E.; Li, J.; Ning, S.; Guo, L.; Li, Q. A novel electrochemical sensor based on FeS anchored reduced graphene oxide nanosheets for simultaneous determination of dopamine and acetaminophen. Mater. Sci. Eng. C 2017, 70, 628-636. [CrossRef]

48. Felix, S.; Grace, A.N.; Jayavel, R. Sensitive electrochemical detection of glucose based on Au-CuO nanocomposites. J. Phys. Chem. Solids 2018, 122, 255-260. [CrossRef]

49. Branagan, D.; Breslin, C.B. Electrochemical detection of glucose at physiological $\mathrm{pH}$ using gold nanoparticles deposited on carbon nanotubes. Sens. Actuators B Chem. 2019, 282, 490-499. [CrossRef] 
50. Salamon, J.; Sathishkumar, Y.; Ramachandran, K.; Lee, Y.S.; Yoo, D.J.; Kim, A.R.; Kumar, G.G. One-pot synthesis of magnetite nanorods/graphene composites and its catalytic activity toward electrochemical detection of dopamine. Biosens. Bioelectron. 2015, 64, 269-276. [CrossRef]

51. Kumar, B.; Murali, A.; Giri, S. Upconversion Nanoplatform for FRET-Based Sensing of Dopamine and $\mathrm{pH}$. ChemistrySelect 2019, 4, 5407-5414. [CrossRef]

Sample Availability: Samples of the compounds are not available from the authors.

(C) 2019 by the authors. Licensee MDPI, Basel, Switzerland. This article is an open access article distributed under the terms and conditions of the Creative Commons Attribution (CC BY) license (http://creativecommons.org/licenses/by/4.0/). 